\title{
Panuveitis and Orbital Inflammation: A Severe Presentation of Acute Retinal Necrosis in a 4 Year-Old Girl
}

\author{
Patrick R Boulos ${ }^{1}$, Mona Harissi-Dagher ${ }^{2}$, Rafic Antonios ${ }^{1}$ and Patrick Hamel ${ }^{3 *}$ \\ ${ }^{1}$ Centre universitaire d'ophtalmologie (CUO), Department of Ophthalmology, Hôpital Maisonneuve-Rosemont, Canada \\ ${ }^{2}$ Department of Ophthalmology, Centre hospitalier de l'Université de Montréal, Canada \\ ${ }^{3}$ Department of Ophthalmology, Hôpital Sainte-Justine, Canada
}

Submission: March 08, 2018; Published: April 03, 2018

*Corresponding author: Patrick Hamel, Hôpital Sainte-Justine, Department of Ophthalmology, 3175, Chemin Côte-Ste-Catherine, Montréal, Québec, Canada H3T 1C5, Tel: (514) 345-4715; Fax: (514) 345-4880; Email: Patrick@hamel.ca

\begin{abstract}
A 4-year-old patient presented with rapidly progressing orbital inflammation, panuveitis and subretinal and intravitreal tumor-like densities. Differentiating a neoplastic from an inflammatory or infectious etiology was a challenge. The final diagnosis was acute retinal necrosis that may have been caused by HSV or EBV.

Keywords: Acute Retinal Necrosis; Retinal Detachment; Enucleation
\end{abstract}

\section{Introduction}

Acute retinal necrosis is a rare, yet still potentially blinding disease, especially in patients with atypical presentations. Despite better diagnostic techniques, current diagnosis still relies on clinical appearance and disease course as described by the clinical criteria adopted by the American Uveitis Society [1].

In this report we depict the clinical challenges encountered in diagnosing and differentiating ARN it from a neoplastic or bacterial etiology in a 4-year-old patient who presented with rapidly progressing orbital inflammation, panuveitis and, subretinal and intravitreal tumor-like densities.

\section{Case Report}

An otherwise healthy 4-year-old girl presented to our university-based pediatric ophthalmology clinic for a redhot eye. One week prior to consulting, she suffered an upper respiratory tract infection. Two days before her visit, the conjunctiva of the left eye became erythematous and was treated with polymyxin B/bacitracin. Her vision was normal at that time. A labial herpetic vesicle appeared simultaneously. The next day, she developed left superior eyelid edema that progressed within 24 hours to total lid closure.

On first examination, she was febrile. Her visual acuity has decreased to light perception in the left eye. A maximal relative afferent pupillary defect was present. Both left lids were severely edematous, with a bluish erythema. The eye was proptotic and ductions were restricted. An erythematous chemosis was present, along with corneal edema and stellate keratic precipitates. The anterior chamber was shallow centrally with a severe fibrinous reaction and a hypopion (Figure 1). The intraocular pressure was 12 in the right eye and $38 \mathrm{mmHg}$ in the left. There was no red reflex on indirect ophthalmoscopy.

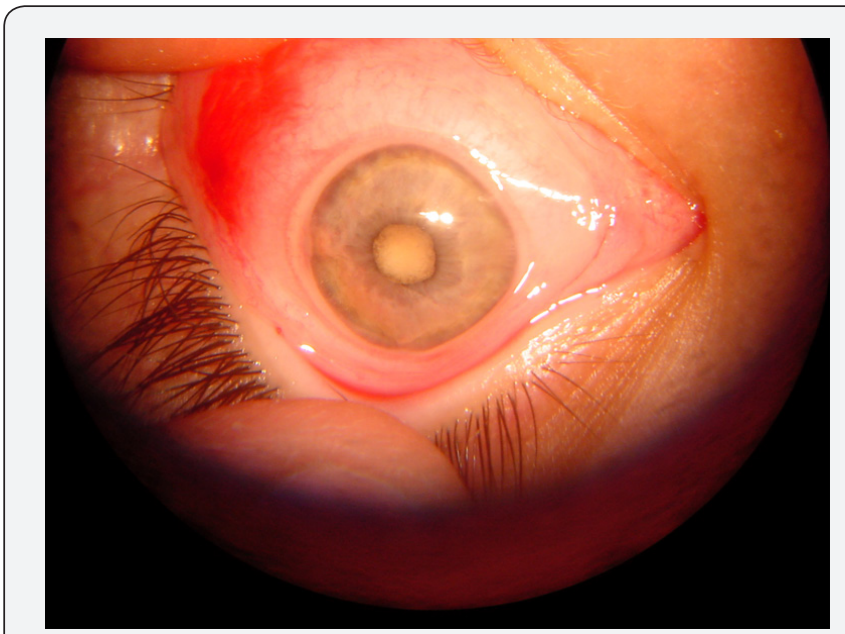

Figure 1: Anterior segment photograph showing the conjunctival erythema and chemosis, along with a shallow anterior chamber and seclusio pupillae secondary to a severe fibrinous reaction. 
A B-Scan (Cinescan, Quantel Medical, France) revealed a total retinal and probable choroidal detachment, debris in the vitreous and a subretinal infiltrate that evoked a neoplastic etiology (Figure 2a).

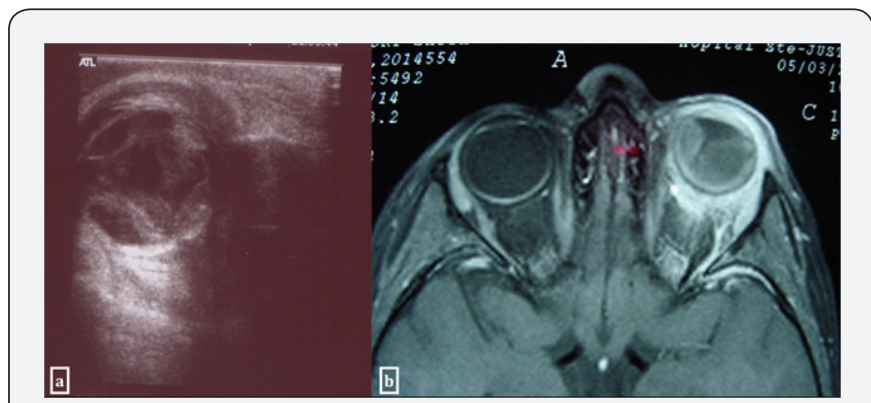

Figure 2: (a) Orbital Ultrasound demonstrating a total retinal and probable choroidal detachment, debris in the vitreous and a subretinal infiltrate that evoked a neoplastic etiology. (b) Axial T1 Fat-suppressed MRI with gadolinium illustrating the positive enhancement of the sclera and subretinal mass simulating a subchoroidal tumor in this 4 year-old girl with panuveitis and orbital inflammation secondary to ARN.

The patient was hospitalized, and although highly improbable, treated as a bacterial orbital cellulitis with IV antibiotics. Prednisolone, homatropine 2\%, timolol $0.5 \%$ and apraclonidine $0.5 \%$ were also given. An orbital and cerebral CT scan showed a hyperdense $8 \mathrm{~mm}$ subretinal mass-like infiltrate, thickened sclera and uvea with contrast enhancement, a slightly enlarged lacrimal gland and, enlarged lateral and superior recti. There were no calcifications. On a subsequent MRI, the mass seemed compatible with a subchoroidal hematoma. Intense periocular inflammation was also noted (Figure 2b).

The day following her admission, the inflammation had progressed. Because of the history of previous herpetic vesicles, she was put on IV Acyclovir and methylprednisolone. After three days on this regimen, the uveitis had decreased substantially. The possibility of acute retinal necrosis was entertained. She was weaned off methylprednisolone. IV acyclovir was continued for 2 weeks and then switched to oral acyclovir for an extra 4 months.

On follow-up, intra-ocular inflammation slowly decreased and subsided and phthisis slowly developed. An enucleation was performed 3.5 months after initial presentation.

Laboratory tests yielded the following results: leucocytosis with a neutrophilic shift, mild lymphopenia, mild anemia, elevated erythrocyte sedimentation rate, $\mathrm{C}$ reactive protein and fibrinogen. All bacterial, fungal and viral cultures from the conjunctiva, urine and blood were negative.

On admission, serologic tests for VZV and HSV were positive for IgG but negative for IgM. Serology for CMV, toxoplasmosis, toxocara, RPR (syphilis) was negative. EBV serology, VCA (viral capsid antigen) and EBNA (Epstein-Barr nuclear antigens) IgG and VCA IgM were negative. A lumbar puncture showed no abnormalities. A bone marrow biopsy was also found to be normal except for a reactive right shift.

The histopathologic exam was consistent with a diagnosis of phthisis bulbi (Figure 3). The retina was totally detached and displayed exudates. The vitreous appeared chronically infiltrated by lymphocytes, plasmocytes and histiocytes. The choroid showed many centers of chronic lymphoid inflammation. These findings were compatible with acute retinal necrosis but were not diagnostic. There were no viral inclusions in the retina.

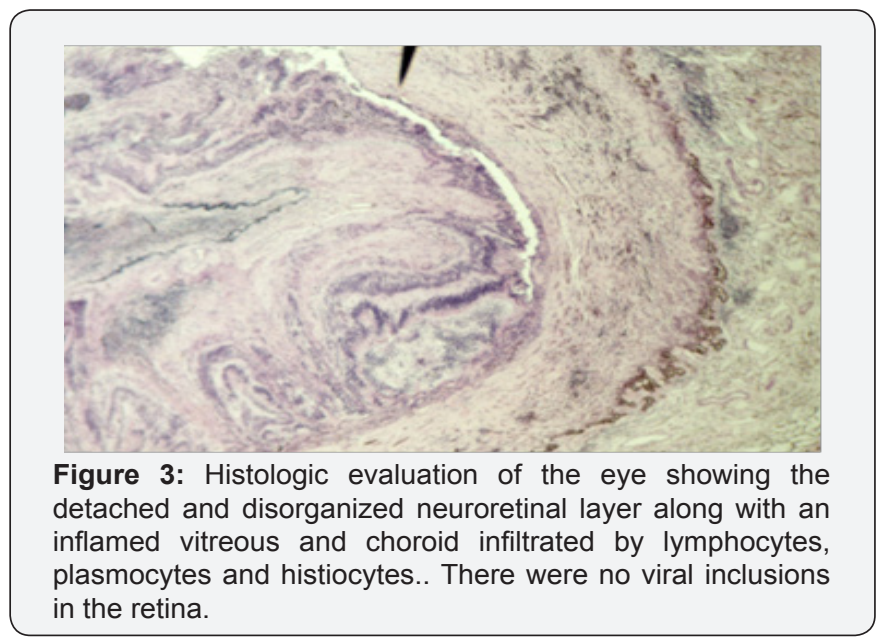

An immunoperoxydase study was done with antibodies directed against CMV and HSV I and II. All were negative. PCR was performed on a vitreous sample to search for DNA or RNA from herpes group viruses. It suggested but did not confirm positivity for EBV considering that serum EBV serology was negative.

\section{Discussion}

This was a misleading clinical case that presented with a subretinal infiltrate evoking a neoplastic etiology, and yet associated with orbital inflammation. There have been many related cases of retinoblastoma and cellulitis-like orbital disease $[2,3]$. Contrary to the case presented here, the intra-ocular tumors occupied between $80-100 \%$ of the globe and had massive central necrosis. One case report described a severe anterior uveitis secondary to a medulloepithelioma [4]. In addition, these tumors can exhibit extra-ocular extension and present initially as orbital cellulitis (Hamel P. et al., Malignant Medulloepithelioma of Optic Nerve in a Child - unpublished). Leukemic infiltration can also occur at this young age but would not display such a severe course.

Overall, the clinical picture did not favor a neoplasm. With a history of fever, reactive neutrophilic leukocytosis and, a very elevated sedimentation rate, $\mathrm{C}$ reactive protein and fibrinogen, the scale tilted toward an infectious or inflammatory etiology.

A primary panuveitis with contiguous orbital inflammation was the best fitting clinical description. The patient had initially developed cutaneous herpes and therefore, acute 
retinal necrosis was the most probable diagnosis. The subretinal tumor was probably secondary to the accumulation of inflammatory and hemorrhagic material. A case of HSV-induced ARN and optic neuritis associated with orbital inflammation has been described [5]. Three documented cases of isolated orbital inflammation caused by VZV have been [6]. The etiology of ARN is VZV in older patients and HSV in younger patients [7]. Other etiologies include CMV and EBV.

EBV has been described to cause panuveitis with retinochoroiditis [8]. Two cases of ARN caused by EBV have been reported in immunocompromised hosts [9]. On the other hand, one paper described "normal" control patients with intraocular fluid PCR and serology positive for EBV [10]. Thus, EBV found by PCR may have merely been an incidental finding.

Failure to detect viral inclusions on histopathology does not rule out ARN [4]. Second, most cases of ARN do not show seroconversion because the eye is relatively immunologically isolated [11]. Finally, PCR studies may only stay positive for about 2 or 3 weeks as is the case in viral encephalitis [4]. In this case, PCR was done 3.5 months after the initial symptoms.

It is possible that this was an example of ARN syndrome and orbital vasculitis. Two etiologies remain possible: HSV or EBV. It is difficult to determine which is most probable. Nevertheless, the patient responded to combined acyclovir and methylprednisolone. Unfortunately, the eye had already sustained irreparable damage.

\section{Conflict of Interest}

None.

\section{References}

1. Kanoff, J. and L. Sobrin (2011). "New diagnosis and treatment paradigms in acute retinal necrosis." International Ophthalmology Clinics51(4): 25-31

2. Mullaney PB, Karcioglu ZA, Huaman AM, Al-Mesfer S (1998). Retinoblastoma associated orbital cellulitis. Br J Ophthalmol82(5): 517-21.

3. Shields JA, Shields CL, Suvarnamani C, Schroeder RP, DePotter P (1991). Retinoblastoma manifesting as orbital cellulitis. American Journal of Ophthalmology 112(4):442-9.

4. Brownstein S, Barsoum-Homsy M, Conway VH, Sales C, Condon G (1984). Nonteratoid medulloepithelioma of the ciliary body. Ophthalmology 91(9):1118-22.

5. Tornerup NR, Fomsgaard A, Nielsen NV (2000). HSV-1-induced acute retinal necrosis syndrome presenting with severe inflammatory orbitopathy, proptosis, and optic nerve involvement. Ophthalmology 107(2):397-401.

6. Vardy SJ, Rose GE (1994). Orbital disease in herpes zoster opthalmicus. Eye 8 (pt. 5):577-579.

7. Duker JS, Blumenkranz MS (1991). Diagnosis and Management of the Acute Retinal Necrosis (ARN) Syndrome. Survey of Ophthalmology 35(5):327-43.

8. Kelly SP, Rosenthal AR, Nicholson KG, Woodward CG (1989). Retinochoroiditis in acute Epstein-Barr virus infection. $\mathrm{Br} J$ Ophthalmol73(12):1002-3..

9. Kramer S, Brummer C, Zierhut M. Epstein-Barr virus associated acute retinal necrosis (2001). Br J Ophthalmol85(1):114.

10. Ongkosuwito JV, Van der Lelij A, Bruinenberg M, Wienesen-van Doorn $M$, Feron EJ, et al. (1998). Increased presence of Epstein-Barr virus DNA in ocular fluid samples from HIV negative immunocompromised patients with uveitis. Br J Ophthalmol82(3):245-51.

11. Pepose JS, Flowers B, Stewart JA, Groce C, Levy DS, et al. (1992). Herpes virus antibody levels in the etiologic diagnosis of the acute retinal necrosis syndrome. Am J Ophthalmol113(3):248-56.

Your next Submission with Juniper Publishers
will reach you the below assets
- Quality Editorial service
- Swift Peer Review
- Reprints availability
- E-prints Service
- Manuscript Podcast for convenient understanding
- Global attainment for your research
- Manuscript accessibility in different formats
( Pdf, E-pub, Full Text, Audio)
- Unceasing customer service
Track the below URL for one-step submission
https://juniperpublishers.com/online-submission.php

